\title{
Unsteadiness in Effervescent Sprays: a New Evaluation Method and the Influence of Operational Conditions
}

JEDELSKÝ, J.; JÍCHA, M.

Atomization and sprays

2008 , vol. 18 , iss. 1 , pp. $49-83$

ISSN: $1044-5110$

DOl: https://doi.org/10.1615/AtomizSpr.v18.i1.20

Accepted manuscript

(c) 2008 Begell House Inc. Final version available from

http://www.dl.begellhouse.com/journals/6a7c7e10642258cc,7da5e43f06d335eb,4319cefd3bbc $\underline{5 d c 2 . h t m l}$ 


\title{
UNSTEADINESS IN EFFERVESCENT SPRAYS - A NEW EVALUATION METHOD AND THE INFLUENCE OF OPERATIONAL CONDITIONS
}

\author{
Jan Jedelsky and Miroslav Jicha \\ Brno University of Technology, Faculty of Mechanical Engineering, Technicka 2, 61669 Brno, Czech \\ Republic, mailto: jedelsky@fme.vutbr.cz
}

\begin{abstract}
A new evaluation method of unsteadiness of the spray generated by an effervescent atomizer is presented. The method is based on measurements of pressure fluctuations in the atomizer mixing chamber. Measurements, made under different atomizer operational conditions, show the spray unsteadiness depends mainly on Gas-to-Liquid-Ratio (GLR). Decrease in GLR causes the spray to become more unsteady. The relation between atomizer internal two-phase flow pattern and the spray unsteadiness is elucidated by visualization of the internal twophase flow using a digital camera and the use of published two-phase flow maps. Findings of the new method are complemented and confronted with the results obtained by the use of spray unsteadiness evaluation method of Edwars \& Marx.
\end{abstract}

\section{INTRODUCTION}

The effervescent atomization technique was developed in the late 1980s by Lefebvre and coworkers [1]. The technology seems promising, although several operation-related issues are known; in particular spray unsteadiness observed under certain operating conditions. An unsteady spray has a negative influence mainly in combustion applications. It leads to a 
combustion noise increase, it raises the load of the combustion chamber, and it can also cause problems in the burner starting sequence.

A few investigators studied the effervescent spray unsteadiness. Roesler and Lefebvre [1] identified a transition from bubbly flow to slug flow and the associated spray unsteadiness. They used this information to define an upper limit to the range of the investigated GLRs. In a subsequent investigation, Whitlow and Lefebvre [2] studied the transition from a bubbly flow to a slug flow in more detail. Chin and Lefebvre [3] observed spray unsteadiness in regimes with a high GLR resulting from the interaction between a liquid film and a high-velocity gas passing down along the central axis of the atomizer mixing chamber. Chen and Lefebvre [4] made a more detailed analysis of this phenomenon and they derived a relation for a maximum GLR value above which the atomizer operation becomes unstable.

Unsteadiness in the slug flow was observed by Catlin and Swithenbank [5]. Using a high speed camera they documented the two-phase flow inside the atomizer mixing chamber, alternating from bubble-froth flow, to annular flow. Discrete bubbles in the froth flow caused bulges followed by explosion-like ruptures in the liquid jet. Confirmation of the unsteady behaviour induced by the slug flow was also made by Jedelsky and Jicha who observed nonuniform internal two-phase flow inside simple plexiglass effervescent atomizer [6].

Luong and Sojka [7] investigated dependence of the effervescent spray unsteadiness on operational conditions, spatial location, and fluid physical properties. Results indicate that the spray unsteadiness is influenced by the GLR and the liquid mass flow rate, depending on the properties of the liquid used in the spray, and that the fluid viscosity and surface tension can affect the level of spray unsteadiness only when the spray is operating in the bubble or 
intermittent slug regimes. The tendency to a higher level of spray unsteadiness was substantiated by transition between bubbly and annular flow, connected with large changes of the void fraction in the two-phase mixture and the existence of liquid bridges between gas bubbles flowing through the exit orifice. Analysis of different droplet size class unsteadiness demonstrated that all droplet classes exhibit unsteady behaviour. The largest droplets are incapable of following the turbulent flow field motions. Gas-phase turbulence can therefore be eliminated as a cause of unsteadiness for those drops. Hence they concluded that effervescent sprays are inherently unsteady. Finally it was found that the spray is more unsteady at its edge, as well as at greater downstream distances. This observation was supported by Bush and Sojka [8] who studied the entrainment characteristics of effervescent atomizer-produced sprays. They concluded that the observed variations in the spray entrainment number were due to different levels of unsteadiness.

With regards to the above mentioned investigations it is clear that the spray unsteadiness is connected with the character of two-phase flow inside the atomizer mixing chamber. Spray tends to be unsteady in regimes where big time changes of void fraction in two-phase mixture flowing through the exit orifice are detected. The mixing of the gas and liquid is a complex process. Inhomogeneous mixture and the resulting spray unsteadiness can be observed under lower GLRs [1, 2, 6, 7] as well as at higher GLR values [3, 4]. Except from fluid properties and atomizer operational condition influence, it is probably also internal construction of the atomizer, which plays an important role. Unfortunately no studies concerning a relation between the spray unsteadiness and the internal atomizer design are known [9].

An ability to quantify the spray unsteadiness is important for detection of an unsteady nozzle operation as well as to enable evaluation of different atomizer versions during atomizer 
design. Until now, several methods have been developed to quantify spray unsteadiness. Edwards and Marx's method [10] uses a comparison of the measured interparticle arrival time distribution with a theoretical distribution function modelled as an inhomogeneous Poisson process. This method was employed by Luong and Sojka [7] and Fritsching and Heinlein [11, 12] to study the effervescent atomizer spray unsteadiness. A planar droplet sizing technique, based on combined measurement of Laser Induced Fluorescence intensity and scattered light intensity of spray droplets was developed and used to quantify the spray unsteadiness of a pressure swirl atomizer by Domann and Hardalupas [13]. The spray unsteadiness is defined as a time-dependent variation of local droplet surface area, liquid volume fraction and droplet SMD. The spatial distribution of the root-mean-square fluctuation is normalized by the corresponding local mean value and the result presents the spray unsteadiness. An alternative method is based on measurements of two-phase mixture pressure fluctuations inside the atomizer mixing chamber [6]. A simplified relation between pressure fluctuations and liquid flow rate fluctuations at the nozzle exit orifice is used to quantify the flow unsteadiness at the nozzle exit. The pressure oscillation based measurement methods were also used by Osakabe and Horiki [14] and other researchers studying the quality of the gas-liquid mixture. Whithlow and Lefebvre [2] used a variation in fluid supply pressures to detect a transition between flow patterns and the spray unsteadiness of the effervescent atomizer.

In this paper, we have applied the Edwards and Marx's method and expanded the method based on pressure fluctuation measurements to a simple effervescent atomizer. This novel measurement method is described here; mainly the simplified relation between the pressure fluctuations and the liquid flow rate fluctuations at the exit orifice is derived in detail and used to quantify flow unsteadiness at the nozzle exit. Light heating oil was atomized, using air as the atomizing medium. Measurements were taken over a wide range of liquid flow rates and 
air gauge pressures. Results obtained by both of the methods are used for comparison as well as for evaluation of the influence of operational conditions on the spray unsteadiness.

\section{EXPERIMENTAL FACILITY}

Experimental equipment includes effervescent atomizer, cold test bench with fluid supply system, Phase/Doppler Particle Analyzer and facility for measurements of the pressure fluctuations.

\section{Atomizer Description}

A simplified transparent Plexiglas version of an industrial effervescent atomizer as described in [6] was used for experiments. Fig. 1 is an outline of its body and a view of the installed nozzle at the test bench. This optically accessible atomizer was mainly designed to allow an internal two-phase flow visualization. The liquid (oil) enters the central orifice on top, while the air enters by side orifices and is injected into the liquid, from each side, through a set of 15 holes with the diameter of $1 \mathrm{~mm}$. The internal diameter of the mixing chamber is $8 \mathrm{~mm}$ and the length, downstream of the last row of air holes, is $80 \mathrm{~mm}$. Both fluids form a mixture, flow downstream and exit the atomizer through an orifice to the ambient atmosphere generating the spray. The exit orifice made of brass plate has a diameter of $2.5 \mathrm{~mm}$ and a length of $0.7 \mathrm{~mm}$. There is a conical junction with the apical angle of $90^{\circ}$ between the orifice and the mixing tube.

The atomizer described and used here is based on an early design with a long mixing chamber. It is necessary to remark that its spray is highly unsteady mainly in case of low GLR values as it will be seen later. This atomizer version is unfit for regular use, but it is suitable 
for new measurement method application and for observation of influence of operational conditions on the spray steadiness.

The atomizer was studied in the vertical position of the main axis. The test bench and the fluid supply system description can be found thereinafter. Physical properties of the atomized liquid - light heating oil and the atomizing medium - air are documented in Table 1.

Ubbelohde viscometer was used to measure fluid viscosity (uncertainty value $7 \%$ ), detach method was used to measure the surface tension (uncertainty value $5 \%$ ). The liquid index of refraction was measured using an Abbe model $G$ refraction meter by Carl Zeiss Jena. Uncertainty of the refraction index value is better than $1 \%$. Physical properties of water as reference medium are taken from literature. The air and oil supplies are controlled separately. Operational conditions of the twin-fluid atomizer with given geometry can be basically described by any two independent parameters. The air gauge pressure and GLR were chosen in our case. Thus other values, liquid pressure, liquid and air flow rates, are dependent upon them. Since one of the goals of this study was to investigate how spray unsteadiness depends on atomizer operational conditions, experiments were performed for several air gauge pressures and GLR values. Temperature, gauge pressure and volumetric flow rates of both fluids were measured.

\section{Test Bench}

A schematic layout of the experimental facility is shown in Fig. 2. It consists of a gear pump (14) that supplies light heating oil from a main fuel tank (16) through filters (15), control valves $(9,10)$ and flow meters (6) into the atomizer (7). A chiller (11) ensures constant oil temperature and hence also its viscosity. The compressed air is delivered, either from the 
central plant, or from a two stage compressor (1), depending on the required pressure through the air chamber (2), filters (4), control valve, check valve (5) and flow meters (6) into the atomizer. Spray is collected in a vessel (12) and returned to the main supply tank by the pump (13). The collector is connected to an oil mist separator that keeps the spray zone free of aerosol but does not disturb the spray. The fuel piping is equipped with a hydraulic shock absorber placed in front of the atomizer. Pressure (3) and temperature (17) readings are taken at the atomizer inlets for both the fuel and the air. The pressure measurements are complemented by the pressure difference measurement (8). Uncertainty in fluid pressure measurements is $2 \mathrm{kPa}$. Uncertainty of fluid pressure difference measurement is $1 \mathrm{kPa}$. Uncertainty of the fluid temperature measurements is $0.7^{\circ} \mathrm{C}$. Uncertainty of the volumetric flow rate measurements is $5 \%$ of measured value. Uncertainty values of the different instruments are taken from their technical specification sheets.

\section{Phase/Doppler Particle Analyser}

Drop size, velocity, and arrival time, used for spray unsteadiness evaluation according to Edwards and Marx's method, were measured using Dantec 1D Phase/Doppler Particle Analyser. Its description can be found in [15]. Measurements were carried out at the nozzle axis $50 \mathrm{~mm}$ downstream of the exit orifice for different atomizer operational pressures and GLR values. Measurements in various axial and radial distances from the nozzle exit were made at the gauge pressure of $0.2 \mathrm{MPa}$ and GLR $2.6 \%$ to evaluate the spatial distribution of the spray unsteadiness. The measurements were repeated 3 times for each particular operational condition or the position in the spray so that an ensemble average of the process could be performed. Data for 65000 particles were acquired for each ensemble member. 


\section{Pressure Fluctuation Measurements}

Small quartz pressure sensor Kistler 601A for measuring dynamic and quasistatic pressures has been used to measure fluctuations of the pressure inside the mixing chamber. Its frequency response is flat up to $50 \mathrm{kHz}$ and the natural frequency is $160 \mathrm{kHz}$, linearity is better than $\pm 1 \%$. The sensor was connected to the mixing channel in position $10 \mathrm{~mm}$ upstream from the exit orifice. The all-pass signal was digitised using NI DAQ PCI-4451 device after an application of an antialising filtration with the cut-off frequency of $2.35 \mathrm{kHz}$. Number of $2^{16}$ signal values sampled with frequency of $5 \mathrm{kHz}$ were recorded to PC.

\section{Two-Phase Flow Visualization}

Qualitative description of the mixing process and two-phase flow patterns inside the atomizer are based on records performed by a high-speed camera and a digital camera. Instantaneous images, presented here, were acquired with Olympus Camedia 3000 camera, using the internal flash with an exposure time $1 / 50000 \mathrm{~s}$. The focal distance to the atomizer was 250 $\mathrm{mm}$ with the camera inclined at an angle of $20^{\circ}$ from the normal to the atomizer larger side to eliminate reflections. A high-speed video sequence was achieved using Redlake MotionPro PCI camera. Detailed description can be found in [6].

\section{ATOMIZER INTERNAL TWO-PHASE FLOW}

As described above, the mixing process and two-phase flow behaviour inside the atomizer mixing chamber has a direct impact on the spray steadiness. Description of effervescent atomizer internal two-phase flow is usually made by means of published maps for a fully developed two-phase flow [3, 5, 16 - 18]. Another possibility is a direct two-phase flow visualization by high-speed cameras. It provides a qualitative characterization of two-phase 
flow patterns and an insight into mixing process [5, 6, 16, 19]. A velocity field inside the mixing chamber can be determined by PIV based methods. A PDA technique can be employed to describe bubble diameter distribution and velocity [20]. Optic, acoustic or electric properties of the mixing fluids are used to characterize bubble distribution, size and void fraction [16]. In this section we document the predicted two-phase flow patterns using modified Baker's map. Instantaneous images of the internal atomizer two-phase flow acquired from a digital camera are used to document real atomizer behaviour.

\section{Two-Phase Flow Maps}

The two-phase flow regimes for fully developed flow reported in literature are often correlated empirically using parameters based on various combinations of fluid flow rates, fluid physical properties and pipe dimensions [21 - 25]. For known (measured) gas and liquid volumetric flow rates $\dot{V}_{g}$ and $\dot{V}_{l}$ and the corresponding densities $\rho_{g}$ and $\rho_{l}$, the gas and liquid mass fluxes $\dot{m}_{g}, \dot{m}_{l}$ per channel cross-sectional area $A$ are:

$$
\begin{gathered}
\dot{m}_{g}=\frac{\rho_{g} \cdot \dot{V}_{g}}{A} \\
\dot{m}_{l}=\frac{\rho_{l} \cdot \dot{V}_{l}}{A}
\end{gathered}
$$

The frequently used Gas-to-Liquid mass ratio, GLR, reads:

$$
G L R=\frac{\dot{M}_{g}}{\dot{M}_{l}}=\frac{\dot{m}_{g}}{\dot{m}_{l}}=\frac{\rho_{g} \cdot \dot{V}_{g}}{\rho_{l} \cdot \dot{V}_{l}}
$$


From many published two-phase flow maps [21 - 26] we choose modified Baker's map for vertical downward two-phase flow with transformed coordinates [22] (see Fig. 3). The coordinates in the map are:

$$
\begin{aligned}
& X=k_{x} \cdot \frac{\dot{m}_{g}}{\dot{m}_{l}} \cdot \lambda \cdot \psi=k_{x} \cdot G L R \cdot \lambda \cdot \psi \\
& Y=k_{y} \frac{\dot{m}_{g}}{\lambda}
\end{aligned}
$$

where $k_{x}$ and $k_{y}$ are constants needed for conversion from Imperial System to SI system. The other parameters read:

$$
\begin{aligned}
& \lambda=\left(\frac{\rho_{g}}{\rho_{a}} \cdot \frac{\rho_{l}}{\rho_{w}}\right)^{1 / 2} \\
& \psi=\frac{\sigma_{w}}{\sigma_{l}}\left(\frac{\mu_{l}}{\mu_{w}} \cdot\left[\frac{\rho_{w}}{\rho_{l}}\right]^{2}\right)^{1 / 3}
\end{aligned}
$$

It is clear that for constant fluid physical properties (given in tab. 1) the value of the $X$ coordinate depends on the GLR and on the gas pressure (it changes the gas density $\rho_{g}$ ). The $Y$ coordinate depends on the gas mass flux and the gas pressure. The influence of the gas pressure and the gas mass flux (or GLR) can be expressed by the direction of the position change in the two-phase flow map. If we assume:

$$
\dot{m}_{l} \approx \frac{1}{\dot{m}_{g}}
$$


then we obtain the influence of the gas pressure on the angle $\beta$ of the position change measured from the $X$ axis (skipping constants):

$$
[\operatorname{tg} \beta]_{p_{g}}=\frac{\partial Y / \partial p_{g}}{\partial X / \partial p_{g}}=\frac{-0.5 \dot{m}_{g} \cdot p_{g}^{-3 / 2}}{0.5 \dot{m}_{l} \cdot \dot{m}_{g}^{-1} \cdot p_{g}^{-1 / 2}}=-\frac{\dot{m}_{g}^{2}}{\dot{m}_{l}} \cdot \frac{1}{p_{g}}=-\frac{\dot{m}_{g}^{3}}{p_{g}}
$$

and the gas mass flux influence is

$$
[\operatorname{tg} \beta]_{G_{g}}=\frac{\partial Y / \partial \dot{m}_{g}}{\partial X / \partial \dot{m}_{g}}=\frac{p_{g}^{-1 / 2}}{-2 \dot{m}_{g}^{-3} \cdot p_{g}^{1 / 2}}=-\frac{\dot{m}_{g}^{3}}{2 p_{g}}
$$

The gas pressure increase, while keeping gas mass flux constant, means an increment of $X$ coordinate and a reasonable decrement of $Y$ coordinate, see Fig. 3. The gas pressure increase, while keeping GLR constant, means an increment of both $X$ and $Y$ coordinates. The gas mass flux increase (or GLR increase) while pressure is kept constant, gives rise to a decrement of $X$ coordinate and an increment of $Y$ coordinate. It leads to a specific distribution of the atomizer operational points when GLR and air gauge pressure vary. It is displayed in Fig. 4 and later in section ,Results“.

\section{Specific Two-Phase Flow Patterns}

The Baker's map with transformed coordinates for a vertical parallel fully developed flow published in [22] and presented on Fig. 4 shows that for low GLR values $(0.3 \%<$ GLR $<15$ $\%$, while $p_{g}=0.4 \mathrm{MPa}$ ) the two-phase flow pattern should be bubble - froth, for very low GLR values (GLR $<0.3 \%)$ it should be nearly plug flow. With a GLR increase the pattern should change to annular $(15 \%<$ GLR $<35 \%)$ and further to dispersed flow (GLR $>35 \%$ ). 
A decrease of pressure (keeping GLR $=10 \%$ ) leads to a shift from bubble - froth to slug plug flow, but for the pressure range $0.1-0.5 \mathrm{MPa}$ used in our experiment, the position change in the chart is not as significant as in case of GLR change in range of 0.7-80\% during the experiment.

It is important to highlight that published two-phase flow maps and also the Baker's map with transformed coordinates used here are constructed for fully developed flow. The two-phase mixture formed inside the effervescent atomizer leaves the nozzle shortly after the intermixture and real two-phase flow patterns can differ from the patterns predicted by published two-phase flow maps $[18,19]$. Results of a two-phase flow visualization using digital camera show different two-phase flow patterns acquired under the atomizer operation with $p_{g}=0.4 \mathrm{MPa}$ and variable GLR of $0.5,3,14$ and $82 \%$. The predicted two-phase flow patterns are marked up in Fig. 4. Actual images of the two-phase flow can be seen in Fig. 5 for GLR $0.5,3,14$ and $82 \%$. Below we comment the observations.

GLR $=0.5 \%$, (Fig. 5a): Air penetrates into the liquid through a set of small holes from both sides with a low velocity, bubbles "slide" along the wall, and the air from the downstream holes increases the volume of the bubbles. The two-phase mixture is non-homogenous in the longitudinal direction and this could be a reason for the spray unsteadiness. The observed flow pattern is bubble-froth, in agreement with Baker's map.

GLR $=3.0 \%$, (Fig. 5b): The air penetrates into the liquid faster than in the previous case. The two-phase flow pattern can be described as bubble-froth, the mixture downstream the air holes is also composed of large volumes of separate phases. The Baker's map also indicates bubble-froth regime. 
GLR $=14 \%$, (Fig. 5c): The two-phase mixture is more homogeneous than in the previous two cases. The observed flow pattern is froth-annular, the Baker's map shows annular pattern.

GLR $=82 \%$, (Fig. 5d): The air enters into the mixing tube in small bubbles in almost perpendicular direction towards the tube axis. The liquid travels partly as an annular film on the walls of the tube and partly is distributed in the air which is passing down along the central axis of the tube. The two-phase flow is not developing or changing downstream of the air holes. In accordance with the Baker's map the flow pattern should be dispersed.

Our observations of the internal two-phase flow show two processes, which lead to a variable void fraction in the nozzle exit and could cause the spray unsteadiness: too large volumes of separated phases (gas bubbles, liquid volumes) and time unsteady two-phase flow where fluctuating pattern of the two-phase flow along the central axis of the mixing tube can be seen. Both phenomena were observed mainly at low GLR.

For more detailed information on vertical and horizontal two-phase flow inside the effervescent atomizer using high-speed camera and digital camera see [6].

\section{SPRAY AND TWO-PHASE FLOW UNSTEADINESS MEASUREMENTS}

\section{Development of Two-Phase Flow Unsteadiness Measurement Method}

A stable spray is from macroscopic point of view characterized by constant liquid and gas flow rates at the exit orifice, invariable spray cone angle and other spray properties. Spray 
unsteadiness level according to [13] is defined as a ratio of root-mean-square of the fluctuating component of the liquid flow rate $\overline{\dot{M}}_{l}^{\prime}$ and the mean liquid flow rate $\overline{\dot{M}}_{l}$ :

$$
U=\overline{\dot{M}}_{l}^{\prime} / \overline{\dot{M}}_{l}
$$

While measurement of the mean liquid flow rate is easy, the measurement of the fluctuating part of the liquid flow rate at the exit orifice or in the spray needs special sensors or techniques like the combined PLIF-PIV system. Our unsteadiness evaluation method employs the measurement of pressure fluctuations inside the atomizer mixing chamber instead of the measurement of the liquid flow rate fluctuating component. Calculation of the unsteadiness by Eq. (11), using pressure fluctuations, is developed below. We will mark it as a "two-phase flow unsteadiness" to distinguish it from the spray unsteadiness measured by other methods directly in the spray.

The liquid and the gas enter into the atomizer mixing chamber of a volume $V$. Their mass flow rate is considered to be constant. The fluids form two-phase mixture flowing downstream to the exit orifice. Two-phase flow pattern according to operational conditions (pressure, GLR) can be bubbly, froth, churn, slug (plug), annular or dispersed [1, 6, 9, 16 18], see section "Specific two-phase flow patterns". Void fraction of the mixture passing the exit orifice fluctuates. It influences the volumetric flow rate through the exit orifice and thereby also the pressure inside the mixing chamber. Actual pressure inside the atomizer mixing chamber can be decomposed to a time-average value $\bar{p}$ and a fluctuating component $p^{\prime}:$ 
Let's assume low pressure fluctuations so that $\bar{p} \gg>p^{\prime}$. Also liquid and gas flow rates through the exit orifice $\dot{M}$ can be separated to a time-average value $\overline{\dot{M}}$ and a fluctuating component $\dot{M}^{\prime}$ :

$$
\begin{aligned}
& \dot{M}_{l 2}=\overline{\dot{M}}_{l 2}+\dot{M}_{l 2}^{\prime} \\
& \dot{M}_{g 2}=\overline{\dot{M}}_{g 2}+\dot{M}_{g 2}^{\prime}
\end{aligned}
$$

where subscript 2 refers to the atomizer exit. For atomizer operational conditions specified by an average pressure $\bar{p}$ and an average liquid flow rate $\overline{\dot{M}}_{l 2}$ the actual gas flow rate is:

$$
\dot{M}_{g 2}=\overline{\dot{M}}_{g 2}+\left(\dot{M}_{l 2}-\overline{\dot{M}}_{l 2}\right) \cdot\left[\frac{\partial \dot{M}_{g}}{\partial \dot{M}_{l}}\right]_{\bar{p}, \bar{M}_{l 2}}=\overline{\dot{M}}_{g 2}+\dot{M}_{l 2}^{\prime} \cdot\left[\frac{\partial \dot{M}_{g}}{\partial \dot{M}_{l}}\right]_{\bar{p}, \overline{\dot{M}}_{l 2}}
$$

The value $\left[\partial \dot{M}_{g} / \partial \dot{M}_{l}\right]_{\bar{p}, \bar{M}_{l 2}}=k_{g}$ is given by specific atomizer operational conditions. Its calculation is based on the knowledge of the relation between liquid and gas flow rates for a given pressure inside the mixing chamber. This function can be easily calculated for a twophase flow discharge according to the theory of separated phases or the theory of non-flashing homogeneous choked flow [26]. Total volume of the mixing chamber is filled with the liquid and the gas: $V=V_{g}+V_{l}$. An actual flow rate of the liquid entering the mixing chamber is equal to the average flow rate and it is also equal to the average flow rate of the liquid exiting the mixing chamber: $\dot{M}_{l 1}=\overline{\dot{M}}_{l 1}=\overline{\dot{M}}_{l 2}$. Similarly for the gas: $\dot{M}_{g 1}=\overline{\dot{M}}_{g 1}=\overline{\dot{M}}_{g 2}$. An actual mass of the gas and mass of the liquid inside the mixing chamber: 


$$
\begin{aligned}
& M_{g}=\int d M_{g}=\bar{M}_{g}+\int\left(\dot{M}_{g 1}-\dot{M}_{g 2}\right) \cdot d t=\bar{M}_{g}-\int \dot{M}_{g 2}^{\prime} \cdot d t=\bar{M}_{g}-k_{g} \int \dot{M}_{l 2}^{\prime} \cdot d t \\
& M_{l}=\int d M_{l}=\bar{M}_{l}+\int\left(\dot{M}_{l 1}-\dot{M}_{l 2}\right) \cdot d t=\bar{M}_{l}-\int \dot{M}_{l 2}^{\prime} \cdot d t
\end{aligned}
$$

If we assume that there is no evaporation of the liquid inside the two-phase mixture and that temperatures of both fluids are equal $T_{g}=T_{l}=T$ then we can describe the processes inside the chamber using the ideal gas law:

$$
p=\frac{M_{g} \cdot R_{g} \cdot T}{V_{g}}=\frac{\left(\bar{M}_{g}-k_{g} \int \dot{M}_{l 2}^{\prime} \cdot d t\right) \cdot R_{g} \cdot T}{V-\left(\bar{M}_{l}-\int \dot{M}_{l 2}^{\prime} \cdot d t\right) / \rho_{l}}
$$

As can be seen in Fig. 6 the fluctuations of the liquid volumetric flow rate are about $5 \%$ of the fluctuations of the gas volumetric flow rate for a wide range of the atomizer operational conditions and it will be neglected in further calculations. The isentropic exponent of the twophase mixture depends on the mixture quality $x$ or GLR value [26]:

$$
\gamma=\left\lfloor x \cdot c_{p g}+(1-x) c_{p l}\right\rfloor /\left\lfloor x \cdot c_{v g}+(1-x) c_{p l}\right\rfloor
$$

where

$$
x=(1+1 / G L R)^{-1}
$$

For common operational conditions this exponent is close to 1 (eg. for GLR $10 \%$ is $\gamma=1.015$, see Fig. 7) so that the processes are assumed isothermal. Then: 
$p=\frac{\left(\bar{M}_{g}-k_{g} \int \dot{M}_{l 2}^{\prime} \cdot d t\right) \cdot R_{g} \cdot T}{V-\bar{M}_{l} / \rho_{l}}=\bar{p}-\frac{R_{g} \cdot T \cdot k_{g} \int \dot{M}_{l 2}^{\prime} \cdot d t}{V-\bar{M}_{l} / \rho_{l}}$

The second term in the Eq.(21) represents the fluctuating component of the pressure inside the mixing chamber $p^{\prime}$. Using Eqs. (11) and (21) gives:

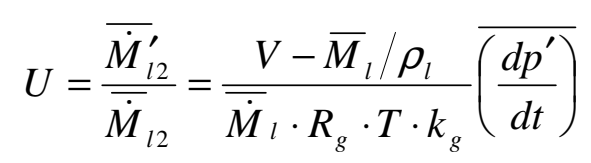

The term $\overline{\left(d p^{\prime} / d t\right)}$ means rms value of the derivative of pressure fluctuations by time and it is calculated using measured pressure fluctuations $p^{\prime}(t)$. Values $V, R_{g}$ and $\rho_{1}$ are constants. Values $\bar{M}_{l}, \overline{\dot{M}}_{l}, T$ depend on atomizer operational conditions and need to be measured. Value $k_{g}$ is calculated according to the theory of non-flashing homogeneous choked flow [26].

Now we have developed the relation for the two-phase flow unsteadiness calculation based on the knowledge of the pressure fluctuations inside the mixing chamber and several other values.

\section{Spray Unsteadiness Measurement Method}

Edwards and Marx [10] developed a theoretical framework for analysis of the time-based multipoint statistics of sprays. Based on this work it is possible to distinguish between steady and unsteady sprays by using the interparticle arrival time $\tau$. Steady sprays according to [10] are defined as those whose interparticle arrival time distribution obey inhomogeneous Poisson 
statistics. Unsteady sprays are those whose interparticle arrival time distribution does not obey inhomogeneous Poisson statistics. An example of unsteady behaviour could be a droplet clustering that occurs e.g. due to liquid jet fragmentation mechanism. The formalism of determining if a spray is steady can be summarized as follows:

- Assumption that the spray is steady and calculation of the interparticle arrival time distribution function,

- measurement of the interparticle arrival times for the spray in question and

○ forming of the corresponding distribution function, comparison of the two functions.

Short description of the evaluation is made hereinafter, for a comprehensive description of the entire calculation procedure see $[7,10]$. The experimental interparticle time distribution $h_{\text {exp }}\left(\tau_{j}\right)$ is determined from several realizations that are ensemble averaged. Edwards and Marx [10] show that:

$h_{\exp }\left(\tau_{j}\right)=\frac{H\left(\tau_{j}\right)}{N \cdot \Delta \tau_{j}}$

Where $\tau_{j}$ is the interparticle time gap $j, H\left(\tau_{j}\right)$ is the number of events that fall within the $j$ th interparticle time gap, $N$ is the total number of interparticle events, and $\Delta \tau_{j}$ is the width of the $j$ th interparticle time gap and is determined by the difference between $\tau_{j}$ and $\tau_{j-1}$. $\tau_{j}$ corresponds to a particular time gap between two particles which is calculated by taking the difference between two particles' arrival time at the probe volume. $H\left(\tau_{j}\right)$ is found by keeping track of the number of times when an interparticle time gap event falls between $\tau_{j}$ and $\tau_{j-1}$. For calculating the experimental distribution the interparticle time has to be divided into bins with a certain width. The binning which is done in a dynamic way was derived by Luong and Sojka [7]. As shown in $[11,27,28]$ there are several sources of errors influencing the number 
of droplets measured in PDA measurements. To reduce this influence the final binning was arranged into bins with a constant width according to [11]: $\Delta \tau=\tau_{j=Q} / Q$. To exclude a bias effect $[11,27]$ by two or more particles coming at the same time into the probe volume the interparticle histograms were calculated starting at some minimum interparticle arrival time. Effervescent sprays are inherently unsteady [7] and the unsteadiness goes over all diameter classes. For that reason $h_{\text {exp }}\left(\tau_{j}\right)$ is evaluated for all the diameter classes together contrary to separated evaluation of individual diameter classes made in $[7,10]$. The ideal spray is modelled, according to [10], as a marked, inhomogeneous Poisson process. The finite theoretical interparticle time distribution is then:

$h_{t h}(\tau)=\frac{\zeta^{2}\left(t_{T}-\tau\right) \cdot \exp (-\zeta \tau)}{\zeta t_{T}-1+\exp (-\zeta \tau)}$

where $\zeta=N / t_{T}$. If the theoretical and the experimental interparticle time distributions are found, their comparison can be made. As a measure of closeness of the observed values to the corresponding expected values the random variable $\chi^{2}$ is calculated:

$\chi^{2}=\sum_{j=1}^{Q} \frac{\left(H\left(\tau_{j}\right)-N \cdot h\left(\tau_{j}\right)\right)^{2}}{N \cdot h\left(\tau_{j}\right)}$

The smaller $\chi^{2}$ value, the better is the agreement between the known data and the proposed model. By other words the $\chi^{2}$ value represents the spray unsteadiness level.

\section{RESULTS AND DISCUSSION}


In the following two subchapters, experimental results of the unsteadiness of the two-phase flow at the nozzle exit and the unsteadiness of the spray will be discussed.

\section{Two-Phase Flow Unsteadiness}

The two-phase flow unsteadiness evaluation method described above was applied to the model effervescent atomizer. The measurements were made for a range of pressures inside the mixing chamber $0.1-0.5 \mathrm{MPa}$ with a step of $0.1 \mathrm{MPa}$ always for several GLR values. The two-phase flow unsteadiness level was calculated according to Eq. (22).

Two different atomizer operational modes were documented in detail:

$\circ$ regime with highly unsteady flow, at pressure $0.2 \mathrm{MPa}$ and GLR $=1.6 \%$;

○ regime with fairly steady flow, at pressure $0.4 \mathrm{MPa}$ and GLR $=14.4 \%$.

Instant fluctuation of liquid flow rate normalized by the mean liquid flow rate was found out using Eq. (22) where instead of rms value of the pressure derivative by time $\overline{\left(d p^{\prime} / d t\right)}$ the actual value $d p^{\prime} / d t$ was used. The normalized value of the liquid flow rate fluctuation for the two different atomizer operational conditions is documented in Fig. 8. Fig. 9 shows a spectral representation of these signals. The fluctuations are seen mainly in frequency range up to 800 $\mathrm{Hz}$, with a maximum about $200 \mathrm{~Hz}$. It indicates the frequency range where increased combustion noise of burner can be expected. Natural acoustic radiation of turbulent premixed flames is broadband, with frequencies from $\sim 100 \mathrm{~Hz}$ to over $20 \mathrm{kHz}$. Typically noise levels peak in the low frequency range of $200-1000 \mathrm{~Hz}$ [29]. There is potential danger of back coupling between the natural and spray induced flame noise radiation. 
Results acquired in the range of operating pressures $0.1-0.5 \mathrm{MPa}$ inside the mixing chamber and a wide range of oil flow rates presented in Fig. 10 show a significant influence of the atomizer operational conditions on the two-phase flow unsteadiness. Fig. 11 documents that the unsteadiness depends virtually only on GLR; the influence of the pressure itself is negligible. The unsteadiness is below 0.09 for GLR higher than $6 \%$, and then, with decreasing GLR, it begins to increase. At GLRs 3\% and lower the unsteadiness is very high and it is also visually observed.

As discussed earlier in the chapter "Specific two-phase flow Patterns" the two-phase flow tends to be inhomogeneous with the GLR decrease. It is documented at regimes with GLR 0.5 $\%$ and $3 \%$ in Figs. 5a, 5b. If the mixing chamber is occupied by large volumes of separated phases then also the resulting mixture flowing through the exit orifice is inhomogeneous. Varying instant GLR or even existence of liquid bridges at the exit cross section leads to varying amount of energy of the compressed atomizing air with respect to the amount of the atomized liquid. Then the discharged mixture consists of larger liquid ligaments followed by discharge of the air with low concentration of smaller droplets. As a result also velocity of the mixture at the exit cross section varies. This finally implicates an unsteady spray and forms a droplet clusters. Our results are consistent with findings in [1, 2, 7].

Investigations of Lefebvre et al. described in $[3,4]$ document spray unsteadiness at higher GLR values in case of the annular flow. In these papers authors observed that most of the liquid flows along the inner wall of the mixing chamber and most of the air flows in the core. At this operating condition the central air void becomes so large that it blocks the whole cross-sectional area of the mixing chamber and the liquid can no longer flow. Eventually the liquid pressure builds up to such an extent that it forces the air void out through the discharge 
orifice. The two-phase flow is then re-established, which causes the air void to reappear and block the mixing chamber again. As the liquid slugs and air voids alternately pass through the orifice, the atomizer operation becomes unstable. In our case the atomizer operated in the annular flow never shown this behaviour. We believe that this unequal behaviour of different effervescent atomizers results from differences in the atomizer designs and/or from the influence of the fluid feeding system.

Now we will try to compare the two-phase flow unsteadiness with other parameters representing the physical processes inside the atomizer. The two-phase flow at the nozzle exit is characterised by a discharge coefficient $C_{d}$ :

$$
C_{d}=\frac{\dot{M}_{l}}{a \sqrt{2 p_{l} \rho_{l}}}
$$

Unlike single-fluid atomizers the exit orifice cross section of the twin-fluid effervescent atomizers is filled in by the liquid and by the gas phases. For a range of the operational conditions of the atomizer used in our experiment the discharge coefficient is driven mainly by the GLR as it is seen on Fig. 12. An increase of the GLR at a given air gauge pressure leads to an increase of the gas flow rate and a blockage of the exit orifice resulting in a decrease of liquid flow rate and thus a decrease of the discharge coefficient. This dependency is typical for effervescent atomizers and is documented in other papers $[4,30]$. Hence there is also a good correlation between the discharge coefficient and the two-phase flow unsteadiness displayed in Fig. 13. Similarly a good agreement can be found for Froude number (Fig. 14), which is in our case proportional to the square root of the GLR: 


$$
F r=\frac{v_{m}^{2}}{g \cdot L}
$$

where $v_{m}$ is the two-phase mixture velocity, $g$ the gravitational acceleration and $L$ the characteristic length of the mixing chamber. By contrast the two-phase flow unsteadiness does not show a significant correlation with Weber number (Fig. 15):

$$
W e=\frac{L \cdot v_{m}^{2} \cdot \rho_{m}}{g_{c} \cdot \sigma_{l}}
$$

where $g_{c}$ is the dimensional constant and $\rho_{\mathrm{m}}$ the mixture density.

The two-phase flow unsteadiness is also compared with regimes of two-phase flow inside the atomizer mixing chamber. The modified Baker's map for the vertical two-phase flow [22] presented in Fig. 16 shows the two-phase flow patterns which should appear in the nozzle in case of the fully developed flow. The level of the unsteadiness is specified by a gray scale, where higher unsteadiness is depicted by a darker grade. The influence of the operational pressure and the GLR on the predicted two-phase flow pattern is described in chapter "Twophase flow map" and graphically presented in Fig.3. Dependence of the unsteadiness on the two-phase flow patterns is unambiguous. The unsteadiness is significant mainly in case of the predicted bubbly flow close to the plug flow. With increasing GLR the two-phase flow pattern should change to frothy and later on to the annular regime, where the unsteadiness has low values. Our observation based on use of high speed camera [6] shows that in case of low GLR the flow inside the mixing chamber is characterised by large volumes of separated phases. It is also documented in Fig. 5 that shows records from the digital camera. We 
conclude that the nonhomogeneous mixture leads to an unsteady mixture behaviour resulting in unsteady liquid discharge.

\section{Spray Unsteadiness}

A representative interparticle time distribution has been plotted as a function of the interparticle arrival time in Fig. 17 to illustrate the comparison between measured and theoretical results. As shown, shorter interparticle time gaps occur more frequently than the theoretical model based on inhomogeneous Poisson process predicts. This indicates a droplet clustering typical for effervescent sprays $[7,11]$. Decomposition into several size classes was made for pressure 0.2 $\mathrm{MPa}$ and GLR $2.6 \%$. Results in Fig. 18 document that all classes behave similarly. Analysis based on the calculation of drop Stokes number shows that the smallest drops should follow the gas-phase turbulence leading to their clustering and hence to possible unsteady behaviour while the biggest drops should not [31]. The contradiction between the assumption and the results led Luong and Sojka [7] to a conclusion that the unsteadiness is not driven by the gas-phase turbulence but by the atomization process itself. Influence of the position in the spray on the $\chi^{2}$ value is documented in Fig. 19. We can see that the spray behaves differently in different axial distances from the exit orifice and also in different radial positions in the spray. Generally the $\chi^{2}$ value is relatively low close to the nozzle axis and it increases with increasing radial distances. The highest $\chi^{2}$ values are seen at the edge of the spray. The results off the nozzle axis are in good agreement with those found in $[7,11,12]$. The increase in the unsteadiness near the nozzle axis with increasing axial distance observed in $[7,11]$ was not seen in our results.

Dependence of the unsteadiness on atomizer operational conditions is investigated at the nozzle axis $50 \mathrm{~mm}$ downstream from the exit orifice and is seen in Fig. 20. The measurement 
was made at the same time and under the same operational conditions as the measurement of the two-phase flow unsteadiness described above. The spray unsteadiness is also compared with regimes of two-phase flow inside the atomizer mixing chamber. Fig. 21 shows that the highest $\chi^{2}$ values (here we remind that higher values of $\chi^{2}$ mean lower agreement between the theoretical and the experimental interparticle time distributions and it implies more unsteady spray) are observed in regimes with high $X$ coordinate values and low $Y$ coordinate values, where the mixture should be in bubbly or almost in plug regime, while in annular or dispersed flow the values of $\chi^{2}$ are lower. This is in good agreement with results acquired by the twophase flow unsteadiness measurement method above. It shows that there is a close coupling between internal two-phase flow behaviour and the spray unsteadiness in case of low GLRs. An increase of $\chi^{2}$ values near the transition between the annular and the frothy two-phase flow regimes can be observed. No such local maximum of the two-phase flow unsteadiness was observed on results shown in figures 11 and 16. Thus we can conclude that this singularity rises in the forming spray after the two-phase mixture discharge.

\section{CONCLUSIONS}

An evaluation method of two-phase flow unsteadiness based on a simplified relationship between pressure fluctuations inside the atomizer mixing chamber and liquid flow rate fluctuations at the exit orifice was developed. The method gives one value, which represents an overall absolute value of the two-phase flow unsteadiness for given atomizer operational conditions. Results acquired with a simple effervescent atomizer show that the nozzle unsteadiness appears if GLR decreases to a value of $6 \%$ and lower, when the internal twophase flow transits from frothy to bubbly and tends to be inhomogeneous. 
Method of Edwards and Marx also applied here confirms conclusions of Luong and Sojka [7] that all drop size classes are unsteady. Also our other findings concerning the dependence of the spray unsteadiness on the position in the spray are in a good agreement with results published in $[7,11,12]$. Both methods - Edwards \& Marx and our newly developed method give similar results in case of low GLRs, where both the spray and the two-phase flow unsteadiness increase. It shows a close coupling between internal two-phase flow behaviour and the spray unsteadiness. The local maximum of the spray unsteadiness found near the transition between the annular and the frothy two-phase flow regime was not evident in the two-phase flow unsteadiness results, hence we conclude that this singularity appears after the two-phase mixture discharges during the spray formation.

Results shown here were acquired with a simple effervescent atomizer. This atomizer gives a highly unsteady spray under the low GLR. Although the atomizer seems useless for a regular operation, it is suitable for evaluation of a new measurement method and for the assessment of the influence of operational conditions on the spray steadiness. Our ongoing research shows a strong effect of the atomizer internal design on the spray steadiness and capability to obtain steady spray also in case of low GLR.

Advantages of both methods - Edwards \& Marx and our newly developed method that uses pressure fluctuations - are apparent from the preceding text. The method based on the interparticle arrival time provides information about the unsteadiness at a given point in the spray, so that spatial changes of the spray unsteadiness can be studied. The method is non intrusive but some limitations given by the measurement system used $[11,27,28]$ should be taken into account. The method based on pressure fluctuation measurements gives an overall information about the unsteadiness for particular nozzle operational condions. It is simple but 
applicable only with atomizers where an internal two-phase flow is formed and only the unsteadiness induced by the two-phase flow can be measured.

\section{ACKNOWLEDGEMENT}

The authors gratefully acknowledge a financial support from the Ministry of Education of the

Czech Republic through the project Eureka E! 2517 BURNER, from Brno University Research Plan No. MSM262100001 and the projects GA 101/03/P020 and GA 101/06/0750 funded by the Czech grant agency.

\section{REFERENCES}

1. T. C. Roesler and A. H. Lefebvre, Photographic studies on aerated-liquid atomization, combustion fundamentals and applications, Proc. of the Meeting of the Central States section of the Comb. Inst., Paper 3, 1988.

2. J. D. Whitlow and A. H. Lefebvre, Effervescent Atomizer Operation and Spray Characteristics, Atomization and Sprays, vol. 3, no. 2, pp. 137-155, 1993.

3. J. S. Chin and A. H. Lefebvre, A Design Procedure for Effervescent Atomizers, J. of Eng. for Gas Turb. and Power, vol. 117, pp. 266-271, 1995.

4. S. K. Chen and A. H. Lefebvre, Discharge coefficients for plain-orifice effervescent atomizers, Atomization and Sprays, vol. 4, pp. 275-290, 1994.

5. C. A. Catlin and J. Swithenbank, Physical Processes Influencing Effervescent Atomizer Performance in the Slug and Annular Flow Regimes, Atomization and Sprays, vol. 11, pp. 575-595, 2001.

6. J. Jedelsky and M. Jicha, Characteristics of a Two-phase Flow Inside the Mixing Chamber of an Effervescent Atomizer, Proc. of 3rd Int. Symp. on Two-Phase Flow Modelling and Experimentation, 2004. 
7. J. T. K. Luong and P. E. Sojka, Unsteadiness in Effervescent Sprays, Atomization and Sprays, vol. 9, no. 1, pp. 87-109, 1999.

8. S. G. Bush and P. E. Sojka, Entrainment by Effervescent Sprays at Low Mass Flowrates. Proc. of the 6th ICLASS, pp. 609-615, 1994.

9. S. D. Sovani, P. E. Sojka and A. H. Lefebvre, Effervescent Atomization, Progress in Energy and Comb. Science, vol. 27, pp. 483-521, 2001.

10. C. F. Edwards and K. D. Marx, Multi-Point Statistical Structure of the Ideal Spray, Part II: Evaluating Steadiness Using the Interparticle Time Distribution, Atomization and Sprays, vol. 5, pp. 475-506, 1995.

11. U. Fritsching and J. Heinlein, Analysis of Single Point Particle Time Series for Detection of Droplet Clustering in Sprays, Proc. of 3rd Int. Symp. on Two-Phase Flow Modelling and Experimentation, 2004.

12. J. Heinlein and U. Fritsching, Droplet Clustering in Sprays, Proc. of 19th ILASS-Europe, pp. 412-417, 2004.

13. R. Domann and Y. Hardalupas, Planar Droplet Sizing for Quantification of Spray Unsteadiness, Proc. of 18th ILASS-Europe, 2002.

14. M. Osakabe and S. Horiki, Estimation of two-phase flow quality with pressure difference oscillation, Proc. of 3rd Int. Symp. on Two-Phase Flow Modelling and Experimentation, 2004.

15. J. Jedelsky, M. Jicha and J. Slama, Characterization of spray generated by multihole effervescent atomizer and comparison with standard Y-jet atomizer, Proc. of 9th ICLASS, pp. 0311, 2003.

16. M. Lorcher, F. Schmidt and F. Mewes, Flow Field and Phase Distribution Inside Effervescent Atomizers, Proc. of 9th ICLASS, pp. 12-9, 2003. 
17. J. S. Chin and A. H. Lefebvre, Flow Regimes in Effervescent Atomization, Proc. of 5th ILASS- Americas, pp. 210-214, 1992.

18. J. S. Chin and A. H. Lefebvre, Flow patterns in internal-mixing, twin-fluid Atomizers, Atomization and Sprays, vol. 3, pp. 463-475, 1993.

19. P. J. Santangelo and P. E. Sojka, A Holographic Investigation of the Near Nozzle Structure of an Effervescent Atomizer Produced Spray, Atomization and Sprays, vol. 5, pp. 137-155, 1995.

20. G. Brenn, H. Braeske and F. Durst, Investigation of the Unsteady Two-Phase Flow with Small Bubbles in a Model Bubble Column Using Phase-Doppler Anemometry, Chem. Eng. Science, vol. 57, pp. 5143-5159, 2002.

21. P. B. Whaley, Two-phase Flow and Heat Transfer, chap. 3, Oxford university press, Oxford, 1996.

22. Process Associates of America, Accessed via WWW. http://www.processassociates.com/process/fluid/2faz_xy.htm, (12 Mar. 2003).

23. P. L. Golan and A. H. Stenning, Two-phase Flow Vertical Flow maps, Proc. Instn. Mech. Engnrs, vol. 184, no. 3C, pp. 110-16, 1969-70.

24. T. Oshinowa and M. E. Charles, Vertical Two-Phase Flow, 1: Flow-Pattern Correlations, Can. J. Chem. Engng, vol. 52, pp. 25-35, 1974.

25. Y. Taitel and A. E. Dukler, A Model for Predicting Flow Regime Transitions in Horizontal and Near Horizontal Gas-Liquid Flow, AIChE J., vol. 22, pp. 47-55, 1976.

26. J. C. Leung and M. Epstein, A Generalized Correlation for Two-Phase Non-Flashing Homogeneous Choked Flow, ASME J. of Heat Transfer, pp. 528-530, 1990.

27. C. F. Edwards, K. D. Marx and W. K. Chin, Limitations of the ideal phase-Doppler system; Extension to spatially and temporally inhomogeneous particle flows, Atomization and Sprays, vol. 4, pp. 1-40, 1994. 
28. I. V. Roismann and C. Tropea, Drops distributions and flux measurements in sprays using phase Doppler technique, 10th Int. Symp. on Appl. of Laser Techn. to Fluid Mech., 2000.

29. R. Rajaram, Preetham and T Lieuwen, Frequency Scaling of Turbulent Premixed Flame Noise, $11^{\text {th }}$ AIAA/CEAS Aeroacoustic Conf., pp. 1-11, 2005.

30. J. Jedelsky, M. Jicha and J. Slama, Discharge coefficient and operational flow characteristics of multihole effervescent atomizer, Proc. of 9th ICLASS, pp. 0310, 2003.

31. J. T. Hodges, C. Presser, A. K. Gupta and C. T. Avedisian, Analysis of Droplet Arrival Statistics in a Pressure Atomized Spray Flame, 25th Int. Symp. on Combustion, The Combustion Institute, pp. 353-361, 1994.

\section{NOMENCLATURE}

a discharge orifice cross-sectional area, $\mathrm{m}^{2}$

A mixing channel cross-sectional area, $\mathrm{m}^{2}$

c specific heat capacity, $\mathrm{J} / \mathrm{kg} \mathrm{K}$

$C_{d} \quad$ discharge coefficient

Fr Froude number

$g$ gravitational acceleration, $\mathrm{m} / \mathrm{s}^{2}$

$g_{c} \quad$ dimensional constant

GLR gas-to-liquid ratio by mass

$H\left(\tau_{j}\right) \quad$ number of events that fall within the $j$ th interparticle time gap, $1 / \mathrm{s}$

$h_{\text {exp }} \quad$ experimental interparticle time distribution, $1 / \mathrm{s}$

$h_{t h} \quad$ theoretical interparticle time distribution, $1 / \mathrm{s}$

$k_{g} \quad$ relation between gas and liquid flow rate

$k_{x}, k_{y}$ constants

L mixing chamber length, m 
$M \quad$ mass, $\mathrm{kg}$

$\dot{m} \quad$ mass flux, $\mathrm{kg} / \mathrm{m}^{2} \mathrm{~s}^{1}$

$\dot{M} \quad$ mass flow rate, $\mathrm{kg} / \mathrm{s}$

$n \quad$ refraction index

$N \quad$ total number of interparticle events

$p \quad$ pressure, $\mathrm{Pa}$

$Q \quad$ number of interparticle bins

$R \quad$ specific gas constant, $\mathrm{J} / \mathrm{kg} \mathrm{K}$

SMD Sauter Mean Diameter, $\mu \mathrm{m}$

$t \quad$ time, $\mathrm{s}$

$T \quad$ temperature, $\mathrm{K}$

$t_{T} \quad$ total measurement time, $\mathrm{s}$

$U$ two-phase flow unsteadiness

$v \quad$ velocity, $\mathrm{m} / \mathrm{s}$

$V \quad$ volume, $\mathrm{m}^{3}$

$\dot{V} \quad$ volumetric flow rate, $\mathrm{m} 3 / \mathrm{s}$

We Weber number

$x \quad$ mixture quality

$X, Y$ coordinates of two-phase flow map

\section{Greek Symbols}

$\beta \quad$ angle of position change in two-phase flow map, rad

$\gamma \quad$ isoentropic exponent of the two-phase mixture

$\Delta \tau_{j} \quad$ width of the $j$ th interparticle time, $\mathrm{s}$ 
$\zeta \quad$ intensity function, $1 / \mathrm{s}$

$\lambda$ dimensionless argument of the two-phase flow

$\mu \quad$ dynamic viscosity, $\mathrm{N} \mathrm{s} / \mathrm{m}^{2}$

$\rho \quad$ density, $\mathrm{kg} / \mathrm{m}^{3}$

$\sigma \quad$ surface tension, $\mathrm{N} / \mathrm{m}$

$\tau \quad$ interparticle arrival time, $\mathrm{s}$

$\Psi$ dimensionless argument of the two-phase flow

$\chi^{2} \quad$ Chi-square value

\section{Subscripts}

1 at the atomizer inlet

2 at the atomizer exit

a air

$g \quad$ atomizing gas

$j \quad$ index number

$l \quad$ atomized liquid

$m \quad$ two-phase mixture

$p \quad$ at constant pressure

$v \quad$ at constant volume

w watter

\section{Superscripts}

( )’ fluctuating value

( ${ }^{-}$) root-mean-squared fluctuating value 
$\left(^{-}\right)$time-averaged mean value 


\section{LIST OF TABLES}

Table 1 Physical Properties of Fluids at Approximately Room Temperature. 
Table 1 Physical Properties of Fluids at Approximately Room Temperature.

\begin{tabular}{ccccc}
\hline \multirow{2}{*}{ Fluid } & $\mu$ & $\sigma$ & $n$ & $\rho$ \\
& & & & \\
\cline { 2 - 5 } & $\mathrm{N} \mathrm{s} / \mathrm{m}^{2}$ & $\mathrm{~N} / \mathrm{m}$ & - & $\mathrm{kg} / \mathrm{m}^{3}$ \\
\hline Light Heating Oil & 0.0185 & 0.0297 & 1.488 & 874 \\
\hline Air (normal conditions) & & & 1.000 & 1.23 \\
\hline Water (reference medium) & 0.0010 & 0.0727 & 1.333 & 1000 \\
\hline
\end{tabular}




\section{LIST OF FIGURES}

Fig. 1 Plexiglass atomizer model and its body.

Fig. 2 Schematic layout of experimental facility.

Fig. 3 Modified Baker's map for vertical downward two-phase flow with transformed coordinates according to [22] with marked influence of operational conditions on the twophase flow regimes. Arrows show direction of regime change while the appropriate values increase. AB-SP: line defining transition between bubble and plug or annular and slug pattern, A-BF: transition between annular and bubble-froth pattern, A-D: transition between annular and dispersed pattern.

Fig. 4 Predicted two-phase flow patterns for atomizer operation at air gauge pressure $p_{g}=0.4$ $\mathrm{MPa}$ and varying GLR $=0.5-82 \%$.

Fig. 5 Visualization of two-phase flow inside atomizer mixing chamber by digital camera. Operational pressure $p_{g}=0.4 \mathrm{MPa}$, a) GLR $\left.=0.5 \%, \mathrm{~b}\right) \mathrm{GLR}=3.0 \%$, c) GLR $=14 \%$, d) GLR $=82 \%$.

Fig. 6 Gas and liquid flow-rate change comparing to flow rate value at mean GLR $=0.1, p_{g}=$ 0.2MPa.

Fig. 7 Influence of GLR on isentropic exponent of the two-phase mixture. 
Fig. 8a Fluctuations of liquid flow rate normalized by mean flow rate at $p_{g}=0.2 \mathrm{MPa}$, $\mathrm{GLR}=1.6 \%$. Unsteady atomizer behaviour.

Fig. 8b Fluctuations of liquid flow rate normalized by mean flow rate at $p_{g}=0.4 \mathrm{MPa}$, GLR $=14.4 \%$. Steady atomizer behaviour.

Fig. 9a Frequency spectrum of fluctuations of liquid flow rate normalized by mean flow rate at $p_{g}=0.2 \mathrm{MPa}, \mathrm{GLR}=1.6 \%$. Unsteady atomizer behaviour.

Fig. 9b Frequency spectrum of fluctuations of liquid flow rate normalized by mean flow rate at $p_{g}=0.4 \mathrm{MPa}, \mathrm{GLR}=14.4 \%$. Steady atomizer behaviour.

Fig. 10 Dependence of the two-phase flow unsteadiness on the oil flow rate at different air gauge pressure.

Fig. 11 Dependence of the two-phase flow unsteadiness on the GLR at different air gauge pressure.

Fig. 12 Dependence of the discharge coefficient on the GLR at different air gauge pressure.

Fig. 13 Dependence of the two-phase flow unsteadiness on the discharge coefficient at different air gauge pressure.

Fig. 14 Dependence of the two-phase flow unsteadiness on the Froude number at different air gauge pressure. 
Fig. 15 Dependence of the two-phase flow unsteadiness on the Weber number at different air gauge pressure.

Fig. 16 Two-phase flow unsteadiness with respect to atomizer internal two-phase flow patterns.

Fig. 17 Comparison of experimentally acquired and theoretical interparticle time distribution. $p_{g}=0.1 \mathrm{MPa}, \mathrm{GLR}=5.2 \%$, measured in position $50 \mathrm{~mm}$ downstream the exit orifice at the nozzle axis.

Fig. 18 Unsteadiness of different drop size classes, $p_{g}=0.2 \mathrm{MPa}, \mathrm{GLR}=2.6 \%$, measured in position $100 \mathrm{~mm}$ downstream the exit orifice at the nozzle axis.

Fig. 19 Chi-square values at different spray positions, $p_{g}=0.2 \mathrm{MPa}, \mathrm{GLR}=2.6 \%$.

Fig. 20 Spray unsteadiness for different atomizer operational conditions. Measured in position $50 \mathrm{~mm}$ downstream of the exit orifice at the nozzle axis.

Fig. 21 Chi-square values $50 \mathrm{~mm}$ downstream the exit orifice with respect to atomizer internal two-phase flow patterns. 


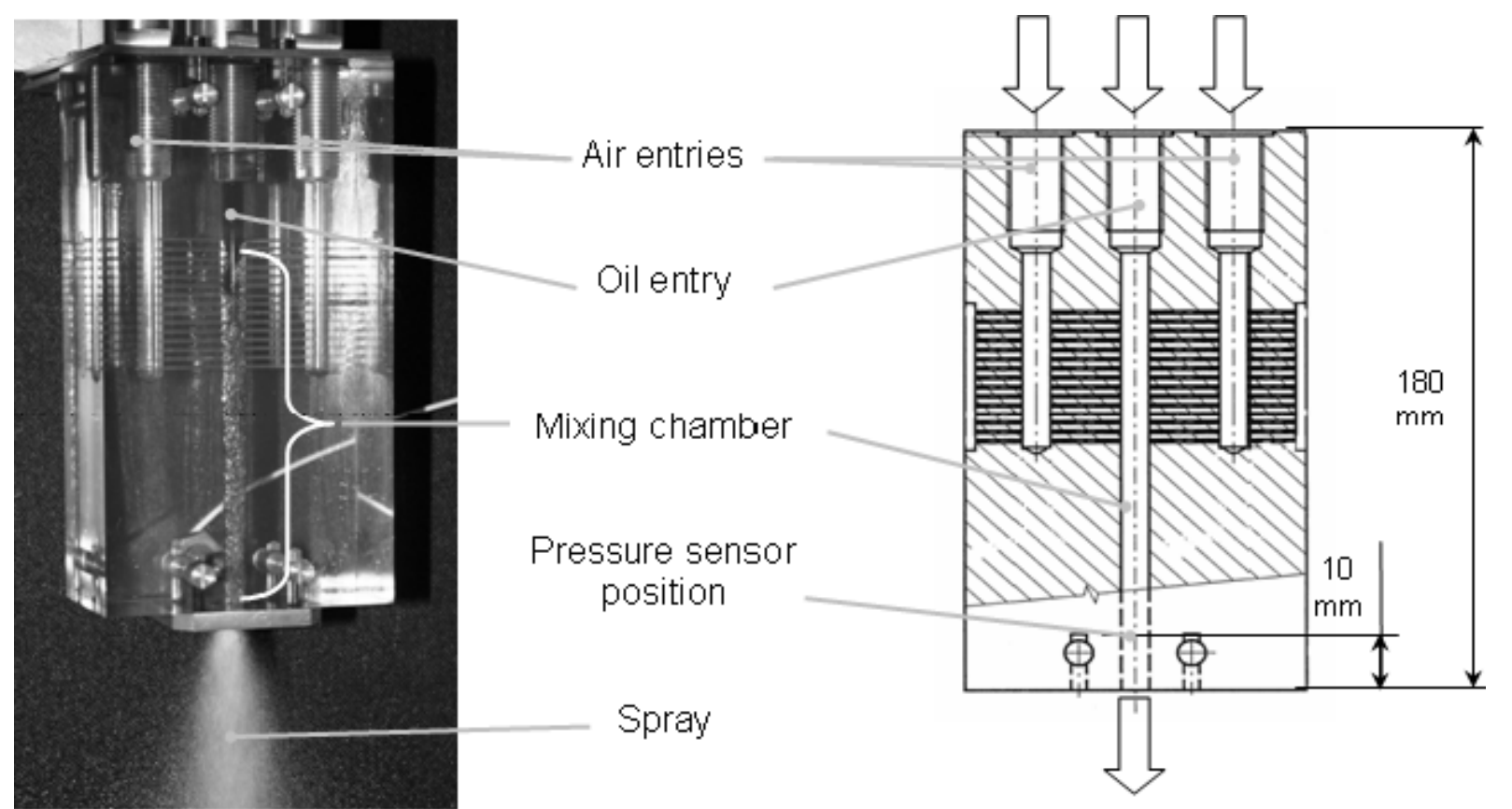

Fig. 1 


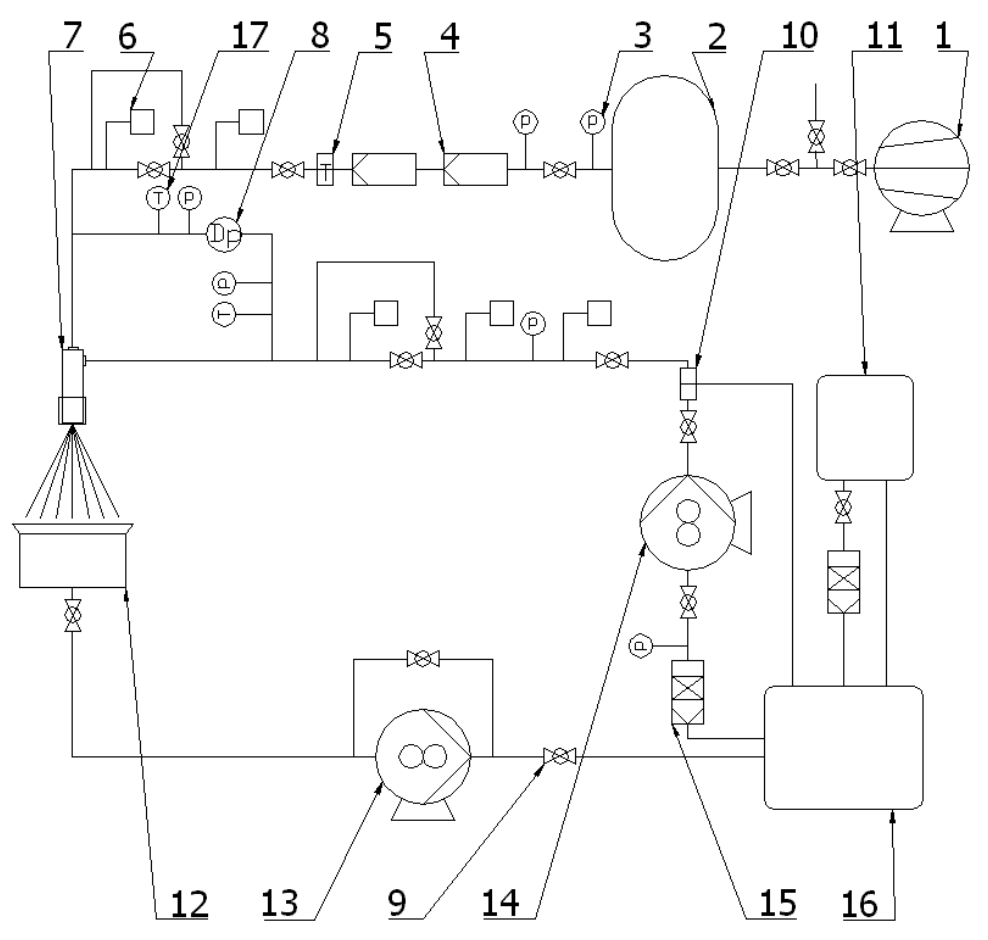

Fig. 2 


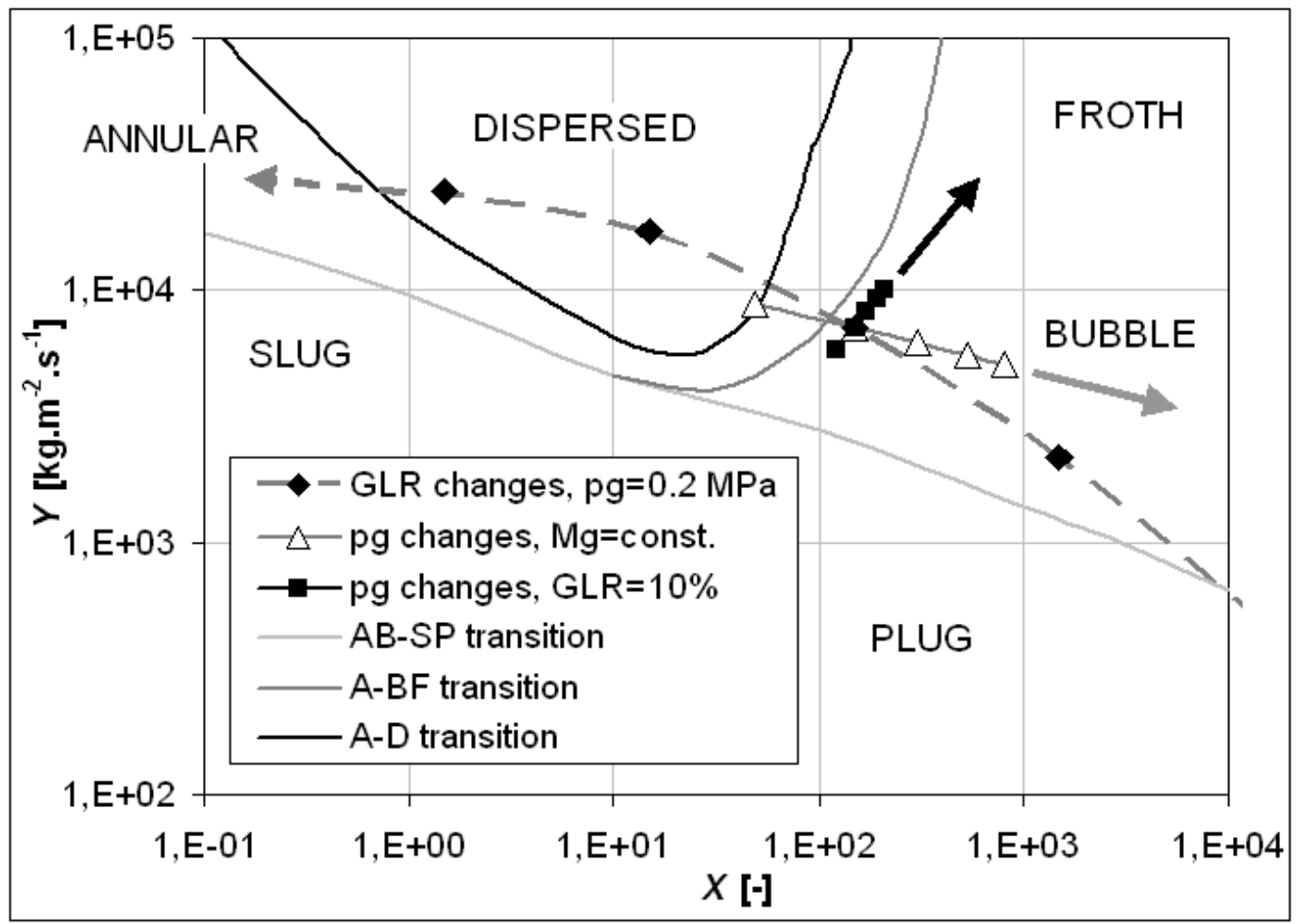

Fig. 3 


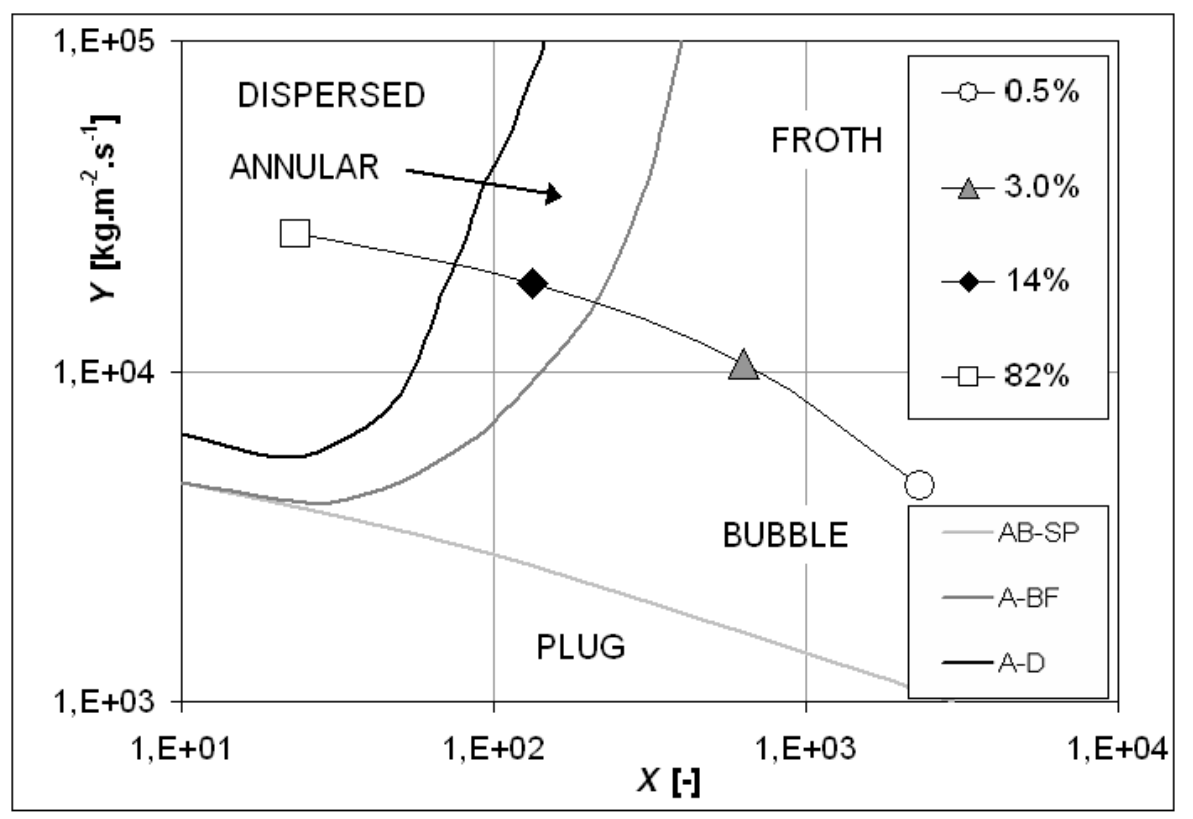

Fig. 4 


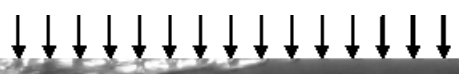

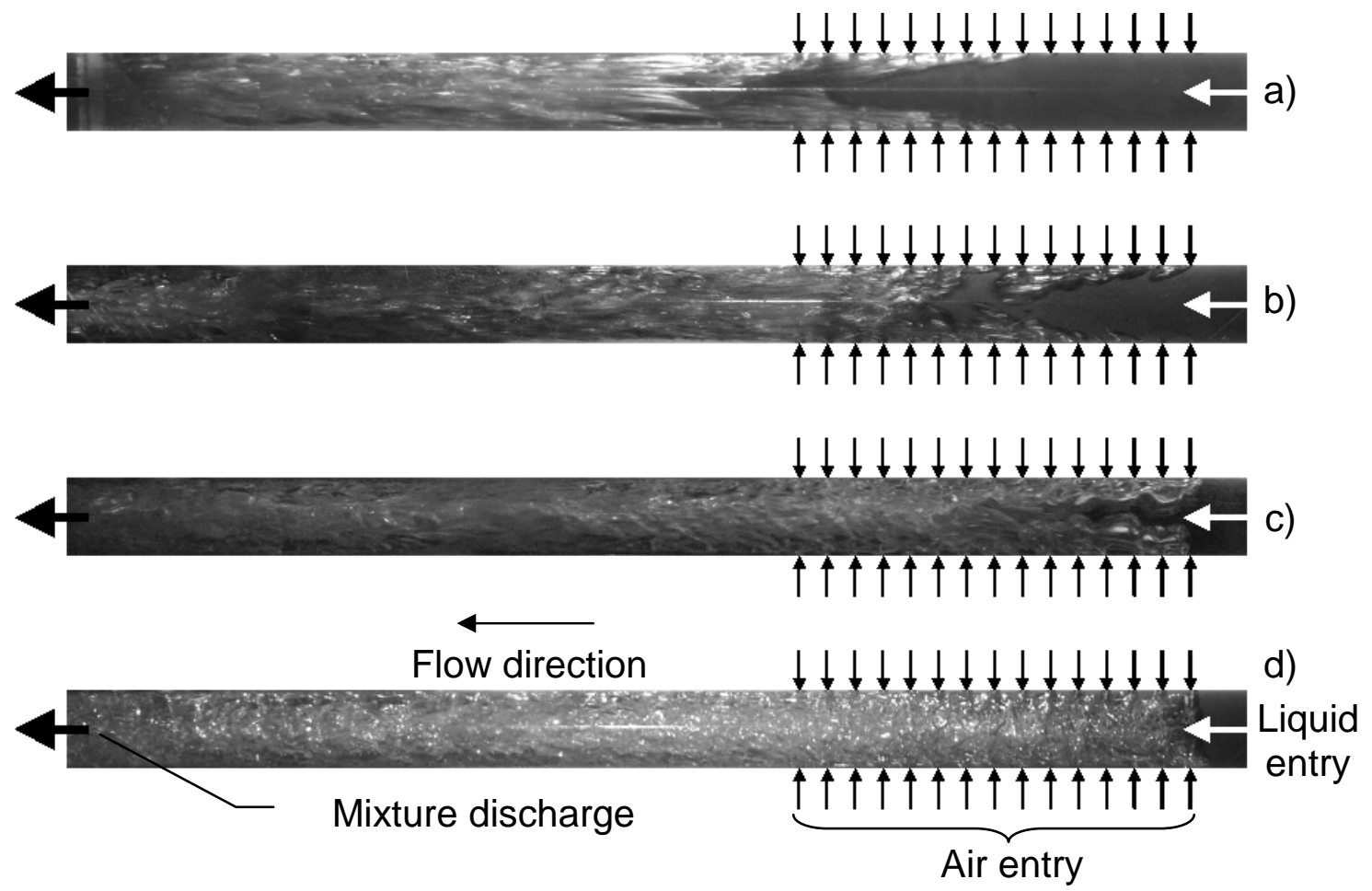

Fig. 5 


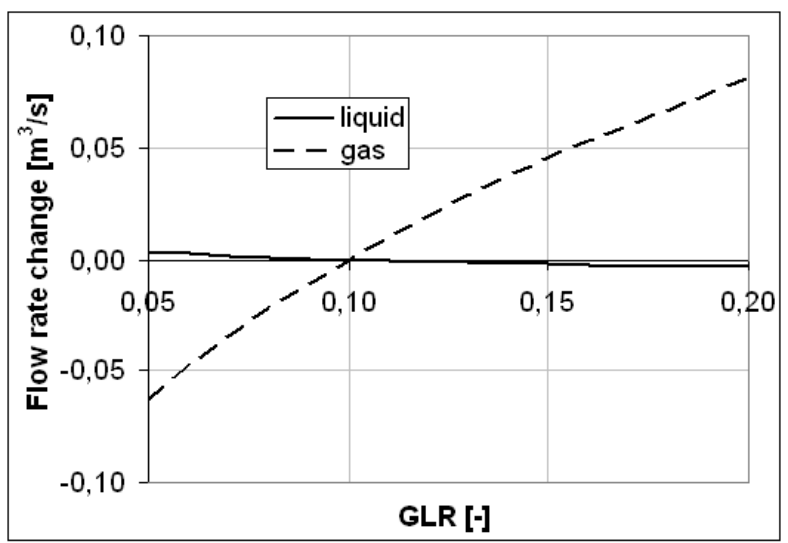

Fig. 6 


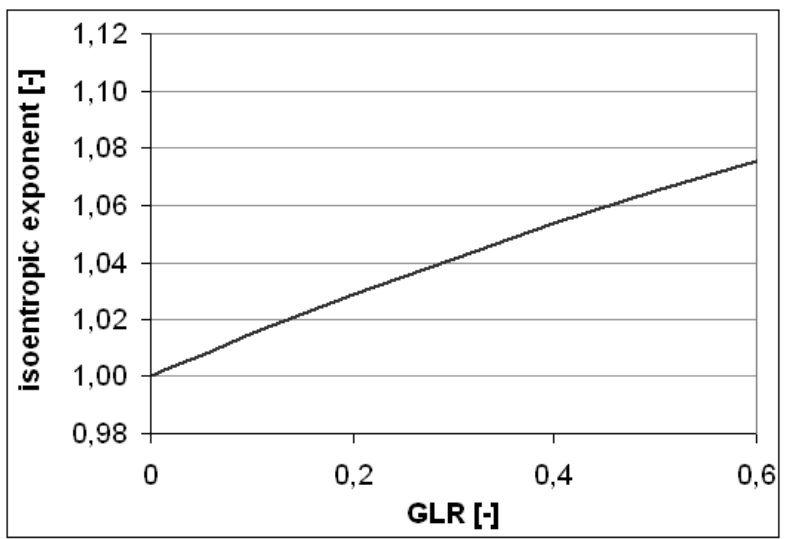

Fig. 7 


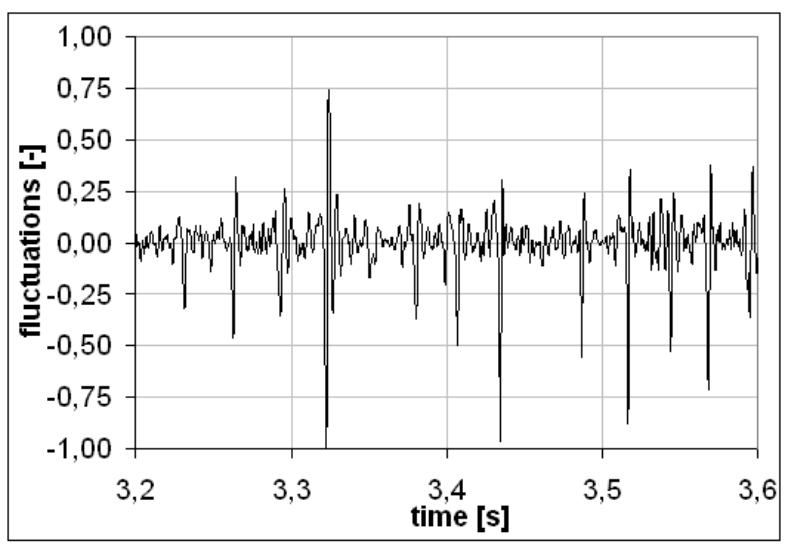

Fig. 8a 


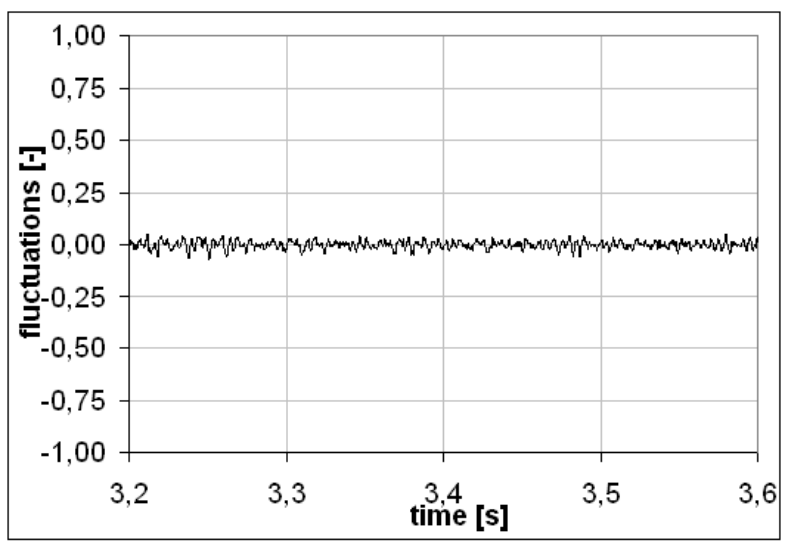

Fig. 8b 


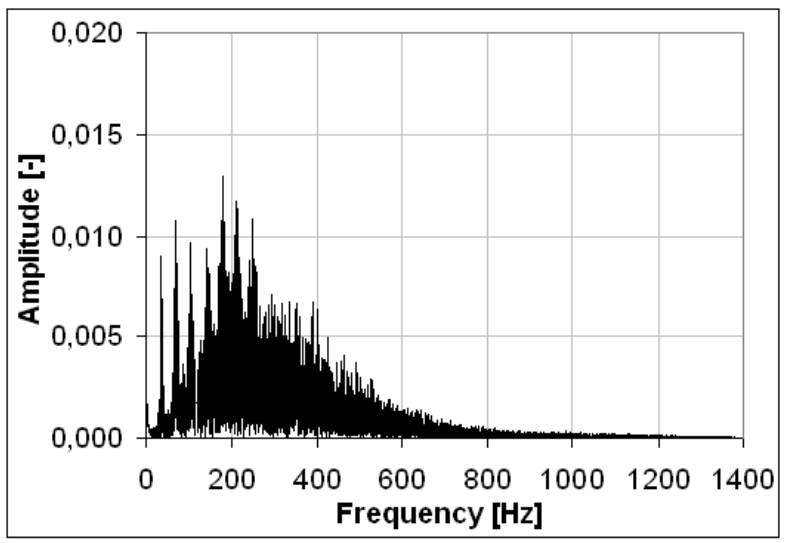

Fig. 9a 


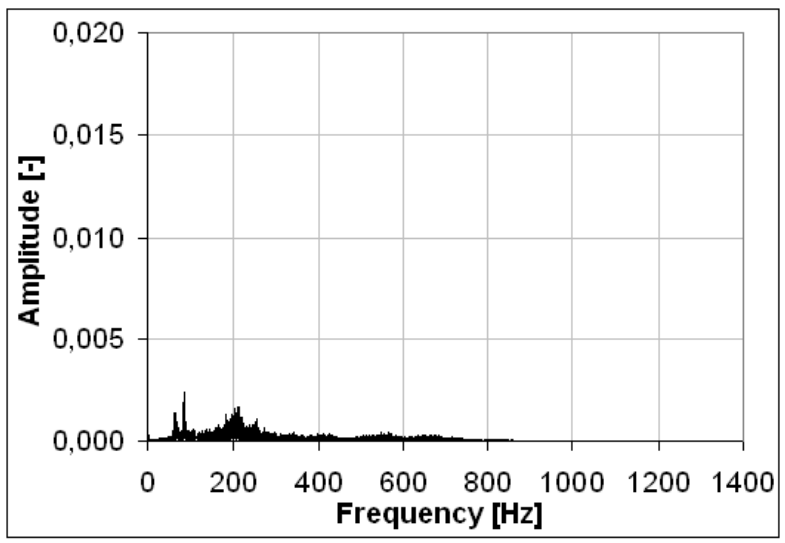

Fig. 9b 


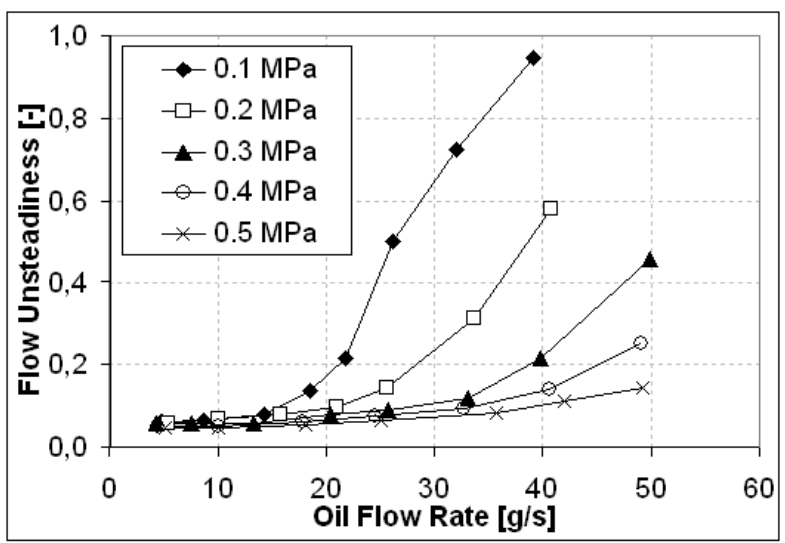

Fig. 10 


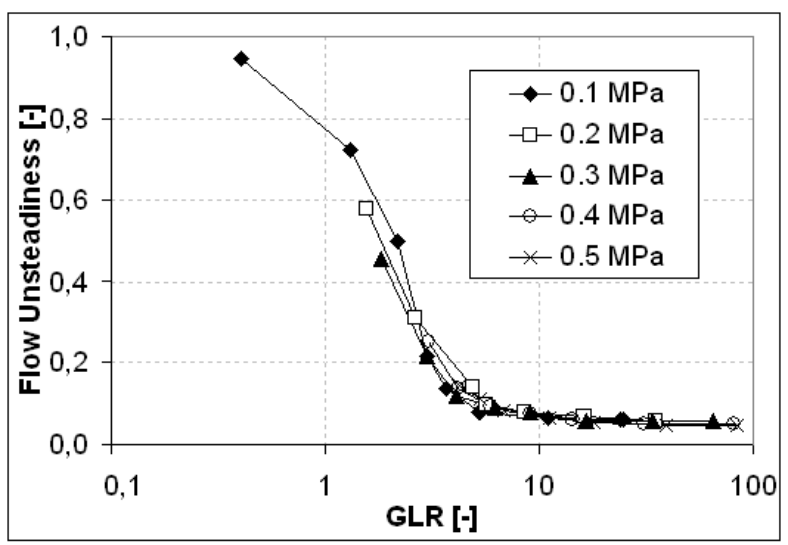

Fig. 11 


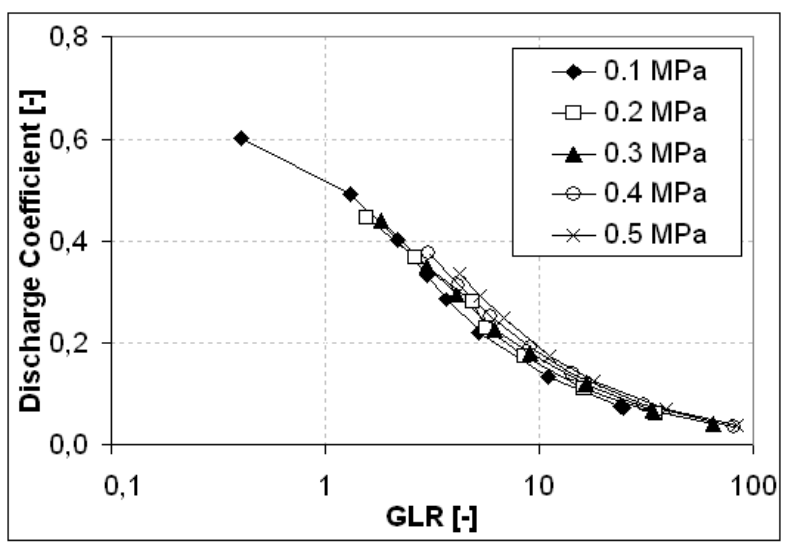

Fig. 12 


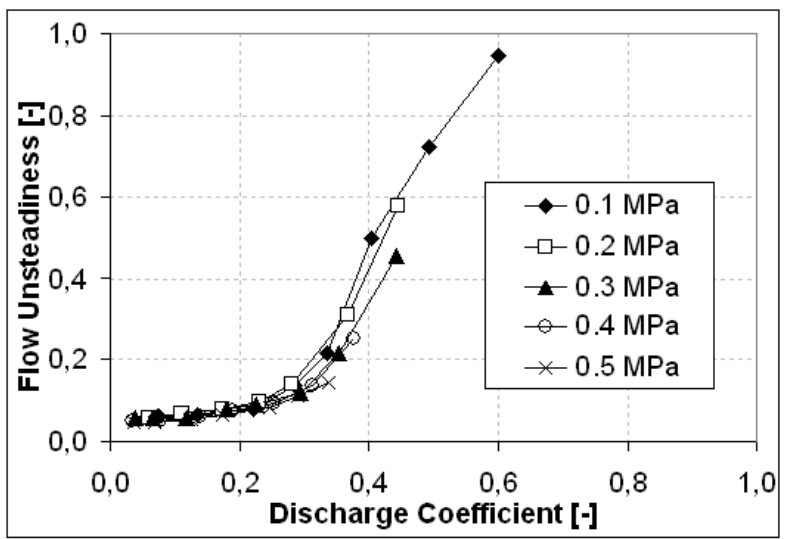

Fig. 13 


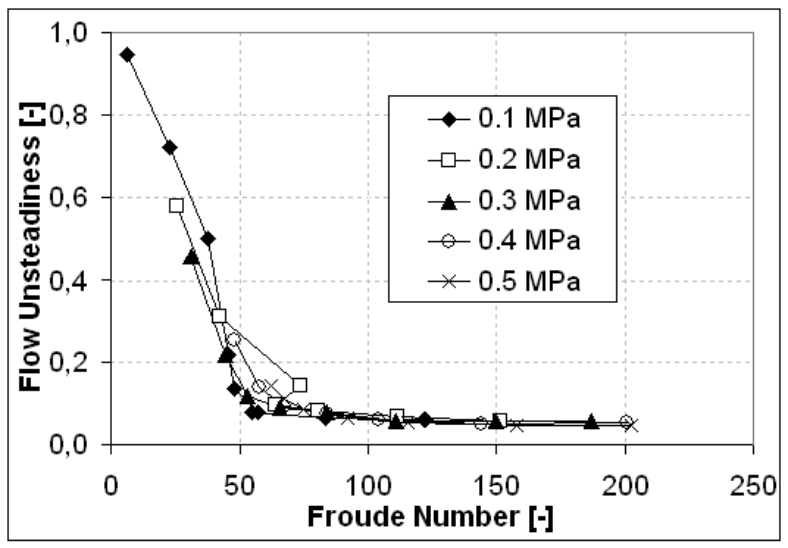

Fig. 14 


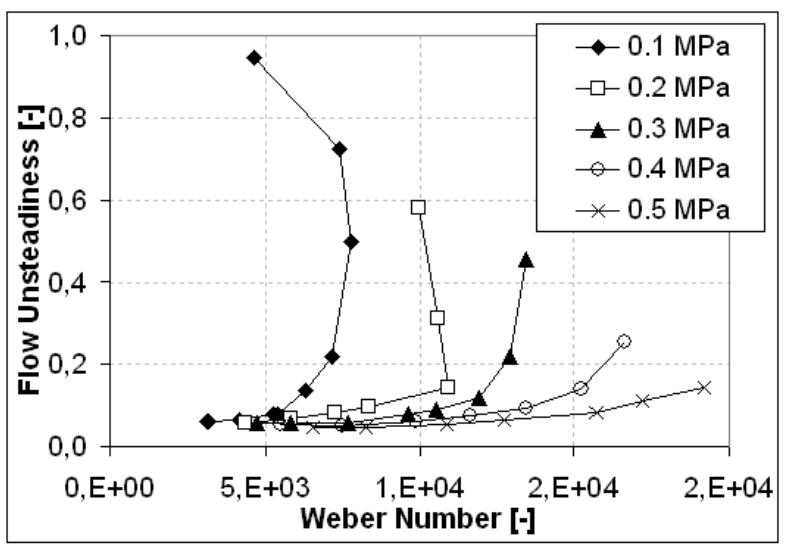

Fig. 15 


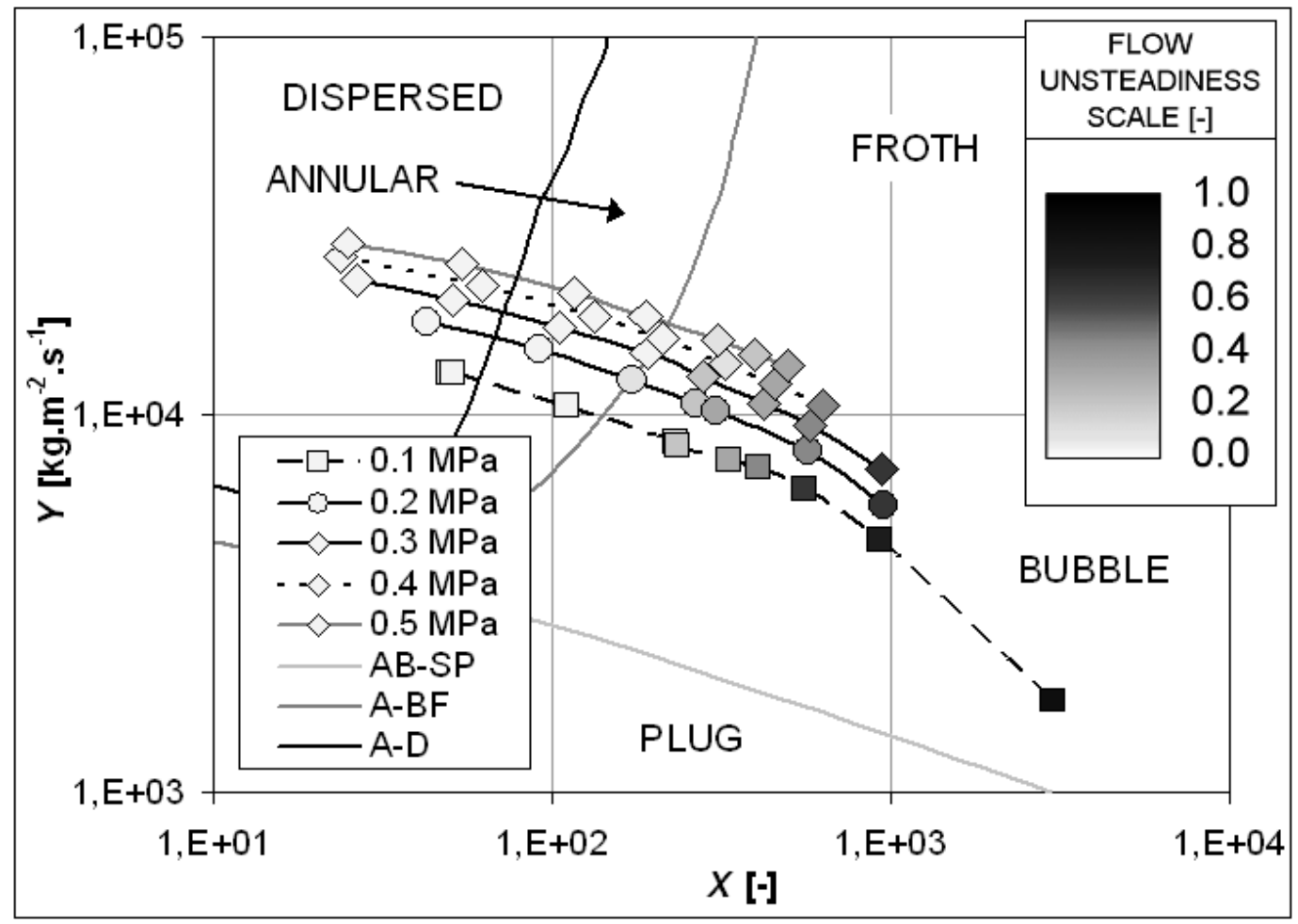

Fig. 16 


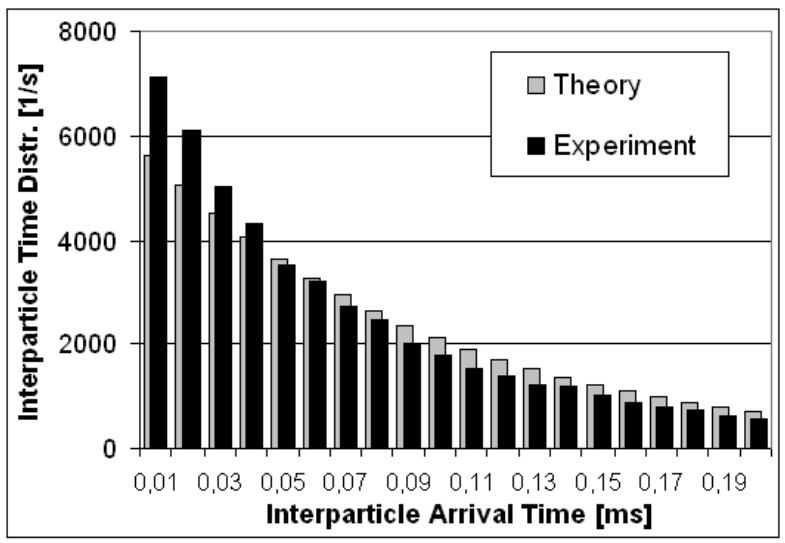

Fig. 17 


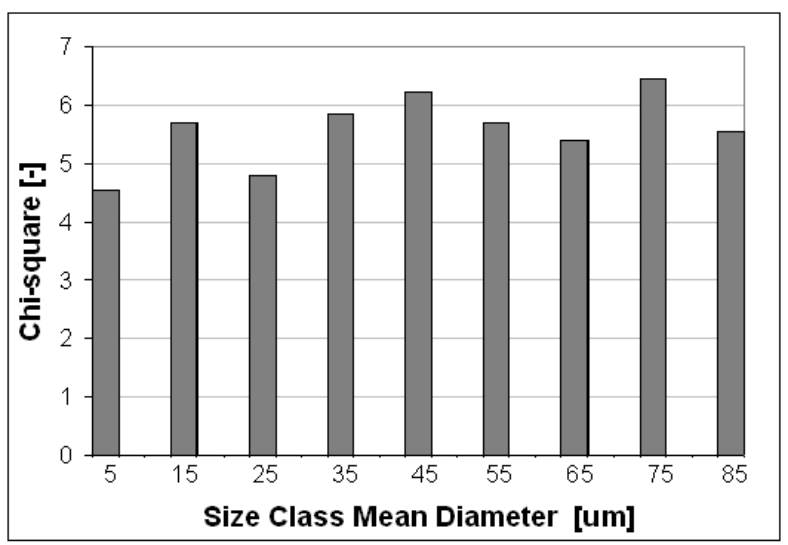

Fig. 18 


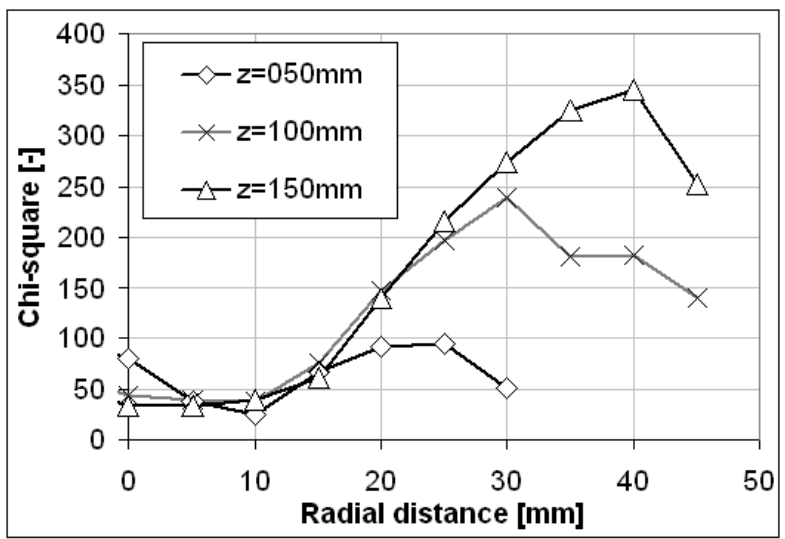

Fig. 19 


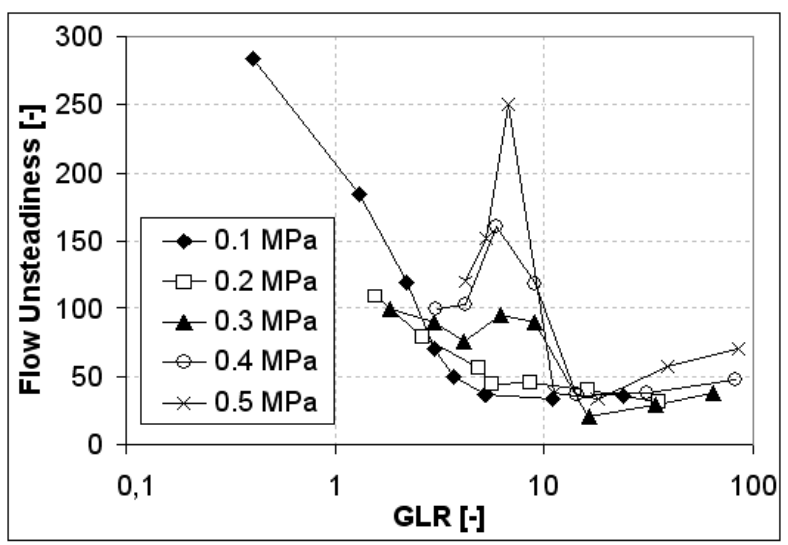

Fig. 20 


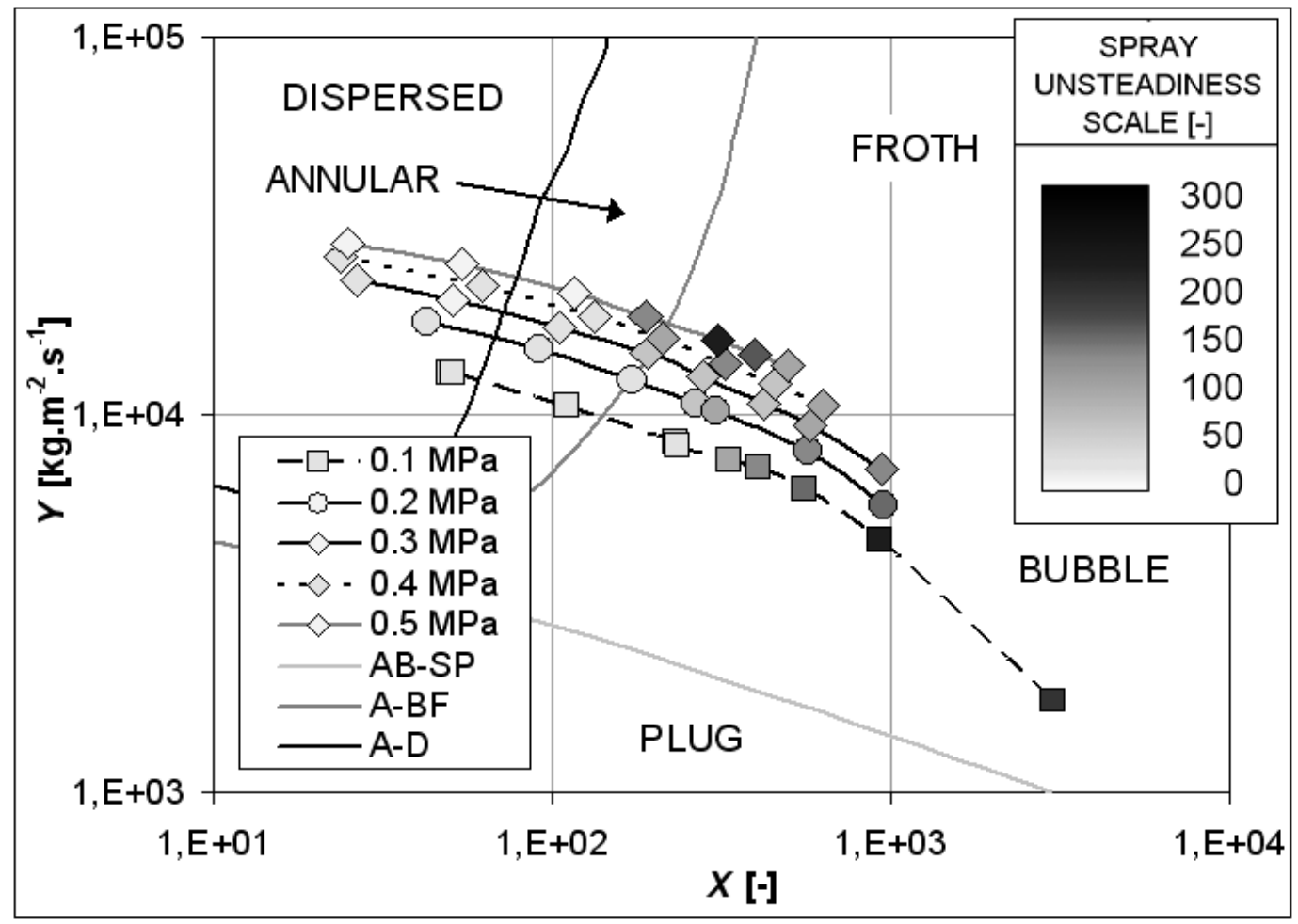

Fig. 21 